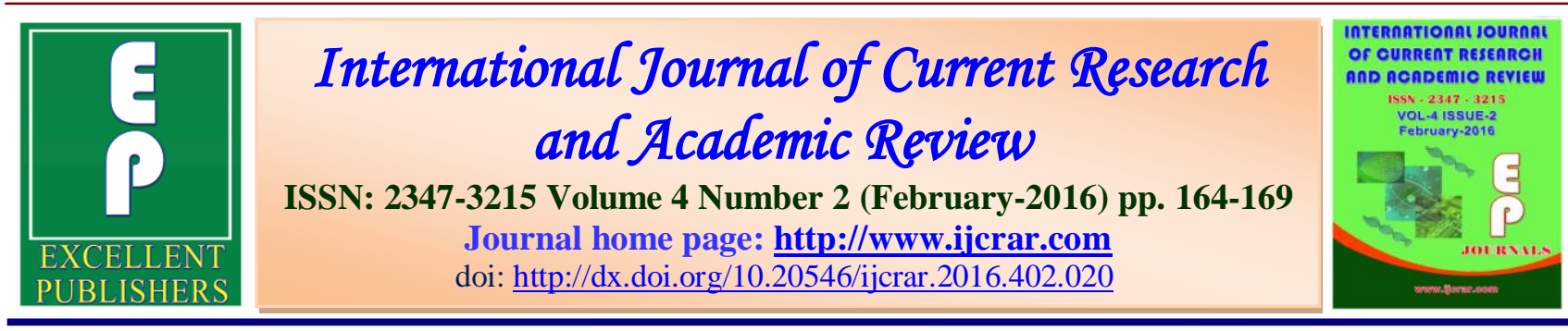

\title{
A Comparative Study of Lipid Profile in Vegetarians and Fish eaters of Selected Areas in Coastal Karnataka, India
}

\author{
Asha Prabhu ${ }^{1,3}$, Manjula Shantaram ${ }^{2,3^{*}}$ and H.P.Kedilaya ${ }^{1}$ \\ ${ }^{1}$ Department of Biochemistry, Srinivas Institute of Medical Sciences \& Research Centre, \\ Srinivasnagar, Mukka, Surathkal, Mangalore, Karnataka, India \\ ${ }^{2}$ Department of Studies in Biochemistry, PG Centre, Mangalore University, Chikka Aluvara, \\ Kodagu, Karnataka, India \\ ${ }^{3}$ Yenepoya University, Mangalore, Dakshina Kannada, Karnataka, India \\ *Corresponding author
}

KEYWORDS

Fish diet,

Vegetarians,

Cholesterol,

Lipoproteins,

Triglycerides,

Cardiovascular

diseases
A B S T R A C T

Dietary intake of fish is associated with reduced risk of cardiovascular disease. However, the contradictory statements on the beneficial effect of fish are the main rationale of this study. The study was conducted on general population consuming vegetarian diet and fish diet. The lipid parameters of 32 vegetarian and 30 fish eating population of age group 25-40 years were studied by estimating Total Cholesterol (TC), HDL- Cholesterol (HDL-C) and Triglycerides (TG). LDL- Cholesterol (LDL-C), Non HDL-C and the risk ratios TC: HDL-C, LDL-C: HDL-C and Non HDL-C: HDL-C was calculated. Lipid parameters between two groups were compared using statistical tests. Significant difference was observed between HDL-C, TG, Non HDL-C, TC: HDL-C, LDL-C: HDL-C and Non HDL-C: HDL-C. The levels of TC and LDL-C were decreased in fish eating population. The study concludes that fish diet has a definite beneficial effect over the vegetarian diet in the age group of 25-40 years.

\section{Introduction}

Cardiovascular diseases (CVD) are the major contributors to the global burden of chronic diseases. The burden of CVD is predicted to increase significantly in developing counties by the year 2020. Major causes of the increase in disease are raising rate of hypertension, dyslipidemia, diabetes, overweight, obesity, physical inactivity, tobacco use, rapid urbanization and change in life style (Reddy et al., 2006; Krishnan, 2012; Tsutsumi, 2015; Najafi and Sheikhvatan 2013). India is experiencing a process of rapid epidemiological transition in terms of patterns of health and disease as communities transform their social and economic structures. There have been marked changes in the diet and lifestyle characteristics of Indian people, resulting in a rapid emergence of CVD (Bulliyya, 2002). 
Lipid abnormalities are associated with cardiovascular diseases. Low HDL Cholesterol (HDL-C), high LDL-Cholesterol (LDL-C) and abnormal triacylglycerol (TAG) are associated with a high risk of cardiovascular disease (Lozano et.al., 2008). The assessment of lipid ratio is very essential even in normal individuals. High serum cholesterol, LDL-C, decreased HDL$\mathrm{C}$, hypertension, diabetes, smoking and family history are the risk factors of coronary artery disease (Kumar and Sivakansan, 2008; Kondreddy, et al., 2012; Upadhyaya, 2015).

Fish and fish oil contain $\omega-3$ fatty acids which protect the individuals from coronary heart disease. The reduction in sudden cardiac death is due to the antiarrythmic activities, reduction of thrombic and inflammatory process and serum triacylglycerol level (Minihane, 2013; Roatz et .al. 2013;Begg et al.,2012).

Fish diet is also recommended to the people with pre-existing coronary artery disease and high triglyceride level (Chowdhury, 2012). $\omega-3$ PUFA reduces the CVD risk by regulating the lipoprotein metabolism and reduces the cardiac mortality and morbidity (Ooi, et al., 2015, McLennan. 2014) Consumption of food sources that provide omega-3 fatty acids, especially the long chain fatty acids from marine sources in the diet shows anti inflammatory mechanism and reduces the CVD risk significantly (Xin, et al., 2012). Thus, an attempt has been made to compare the lipid profiles in vegetarians and fish eaters of selected areas of coastal regions in Karnataka.

\section{Materials and Methods}

After obtaining the institutional ethical clearance, thirty two vegetarians and thirty fish eating volunteers in the age group of 2540 years were chosen for the study. The inclusion criteria were - vegetarians: subjects consuming purely lacto vegetarian diet and fish eaters: subjects consuming minimum of 5 fish meals per week along with vegetables and occasionally other meats. The exclusion criteria for both groups were subjects who were smokers, alcoholics, diabetics or hypertensive. Informed consents were taken from the volunteers. Age, height, weight and waist circumference were recorded. Food habits of the subjects were obtained using a questionnaire.

\section{Collection of Sample}

Five ml of venous blood was collected after an overnight fasting of 10-12 hours. Total Cholesterol (TC), High density lipoproteincholesterol (HDL-C) and Triglycerides (TG) parameters were estimated in the serum by using Bio Lis 24i fully automated analyzer-

Serum total cholesterol was estimated by CHOD-PAP method. (Allain et al., 1974). HDL-Cholesterol was estimated by CHODPAP method (Williams et al., 1979). Estimation of plasma triglycerides was done by GPO-PAP method. (Jacobs et al., 1960). LDL-C was calculated using Friedwald's formula (Kanel et al., 2011) which assumes that VLDL-C is present in a concentration equal to $1 / 5^{\text {th }}$ of the triglyceride concentration. LDL-C $=\mathrm{TC}-(\mathrm{TG} / 5+$ HDL-C)

Non HDL cholesterol is defined as the difference between TC and HDL-C and includes all the cholesterol present in lipoprotein particles considered to be atherogenic (Austin, 1991). Risk ratios were calculated as TC/HDL-C, LDL-C/HDL-C and Non HDL-C/HDL-C.

\section{Statistical Analysis}

Two sample independent ' $t$ ' test was used to compare 2 independent groups. 
Int.J.Curr.Res.Aca.Rev.2016; 4(2): 164-169

\section{Results and Discussion}

Anthropometric data of the two groups are presented in Table 1. Both the groups are comparable in age, Body Mass Index (BMI) and Waist Circumference (WC). The lipid parameters TG, HDL-C, Non- HDL-C and atherogenic risk ratios, TC: HDL-C, LDL-C: HDL-C, NonHDL-C: HDL-C has shown significant difference between two groups (Table 2). TC and LDL-C levels were decreased in fish eating population, but not statistically significant. TG and HDL-C values were within the normal limit in both the groups and marginal increase in $\mathrm{TC}$, LDL-C and Non HDL - $\mathrm{C}$ were observed in vegetarians. $\quad \mathrm{TC}>200 \mathrm{mg} / \mathrm{dL} \quad$ (ormal range: $120-200 \mathrm{mg} / \mathrm{dL}), \quad \mathrm{TG}<165(40-$ $165 \mathrm{mg} / \mathrm{dL})$, LDL- C $>130 \mathrm{mg} / \mathrm{dL}, \quad(40-$ $130 \mathrm{mg} / \mathrm{dL}) \quad$ HDL-C $>40 \mathrm{mg} / \mathrm{dL} \quad(40-$ $88 \mathrm{mg} / \mathrm{dL}$ ), Non HDL-C $<160 \mathrm{mg} / \mathrm{dL}$ ). The risk ratio calculated as TC/HDL-C, LDLC/HDL-C, and Non HDL-C/HDL-C were decreased in fish eating population.

Table.1 Anthropometric Data of Two Study Groups (Mean \pm Sd)

\begin{tabular}{|c|c|c|c|}
\hline Parameters & $\begin{array}{c}\text { Fish eaters } \\
(\mathrm{n}=30)\end{array}$ & $\begin{array}{c}\text { Vegetarians } \\
(\mathrm{n}=32)\end{array}$ & $\mathrm{P}$ value \\
\hline Age & $32 \pm 4.24$ & $33 \pm 4.83$ & $\mathrm{P}>0.05$ \\
\hline BMI & $21.8 \pm 6.9$ & $24.0 \pm 4.0$ & $\mathrm{P}>0.05$ \\
\hline WC & $80.75 \pm 10.45$ & $84.17 \pm 11.7$ & $\mathrm{P}>0.05$ \\
\hline & $\mathrm{n}=$ number of subjects \\
BMI = Body Mass Index \\
WC = Waist Circumference
\end{tabular}

Table.2 Lipid Profiles of Vegetarians and Fish Eaters (Mean \pm Sd)

\begin{tabular}{|c|c|c|c|}
\hline Parameters & $\begin{array}{c}\text { Fish eaters } \\
(\mathrm{n}=30)\end{array}$ & $\begin{array}{c}\text { Vegetarians } \\
(\mathrm{n}=32)\end{array}$ & $\mathrm{P}$ value \\
\hline TC mg/dL & $188 \pm 41.5$ & $201 \pm 35.4$ & $\mathrm{P}>0.05$ \\
\hline TG mg/dL & $118 \pm 44.1$ & $154 \pm 35.4$ & $\mathrm{P}<0.05^{*}$ \\
\hline HDL-C mg/dL & $49.5 \pm 8.4$ & $43.8 \pm 5.0$ & $\mathrm{P}<0.05^{*}$ \\
\hline LDL-C mg/dL & $113 \pm 36.69$ & $134.6 \pm 23.6$ & $\mathrm{P}>0.05$ \\
\hline Non-HDL-C mg/dL & $135 \pm 40.70$ & $165 \pm 34.5$ & $\mathrm{P}<0.05^{*}$ \\
\hline TC: HDL-C & $3.85 \pm 1.0$ & $4.67 \pm 0.81$ & $\mathrm{P}<0.05^{*}$ \\
\hline LDL-C: HDL-C & $2.33 \pm 0.84$ & $3.09 \pm 0.54$ & $\mathrm{P}<0.05^{*}$ \\
\hline Non-HDL-C: HDL-C & $2.83 \pm 1.00$ & $3.83 \pm 0.60$ & $\mathrm{P}<0.05^{*}$ \\
\hline n= number of subjects & & \\
* Statistically significant & & \\
TC $=$ Total Cholesterol \\
TG $=$ Triglyceride \\
HDL -C $=$ High Density Lipoprotein Cholesterol \\
LDL-C $=$ Low Density Lipoprotein Cholesterol
\end{tabular}


In this study, the effect of regular dietary intake of fish on the lipid profile was investigated. Results of the study showed significant difference in TG, HDL-C, Non HDL-C and atherogenic risk ratios such as TC: HDL, LDL: HDL and Non HDL-C: HDL-C between vegetarians and fish eaters. Decreased TC, LDL-C, observed in fish eaters compared to vegetarians. Elevated levels of serum TG have long been associated with the risk of CHD (Austin, 1991; Hokanson and Austin 1996). In the present study, $33 \%$ of vegetarians and $20 \%$ of fish eaters showed TG levels above the cut off limit of $165 \mathrm{mg} / \mathrm{dl}$. Significant difference in the TG of the two groups is consistent with the literature findings which show that Omega-3 fatty acids, which are found abundantly in fish oil lowers the plasma TG (Qi et al., 2008).

HDL-C has an inverse relation to the risk of CHD. Persons with HDL-C levels below $35 \mathrm{mg} / \mathrm{dL}$ have a CHD incidence rate of more than 8 times compared to persons with HDL-C levels greater than $65 \mathrm{mg} / \mathrm{dL}$ or above (Tavia et al., 1997). In our study, significant difference in HDL-C levels was observed in the two groups, $27 \%$ of vegetarians and only $7 \%$ of fish eaters had HDL-C levels less than $40 \mathrm{mg} / \mathrm{dL}$. Lower HDL-C values in young men aged 20 and above in whom a CHD subsequently developed (Gofman et al., 1996). Lower HDL-C levels in men aged 40 and above in whom CHD developed later (Goldbourt and Medali, 1997). A hypothetical $1 \mathrm{mg} / \mathrm{dL}$ increment in HDL-C is associated with $2.3 \%$ decrement of CHD risk (Gordon et al., 1989). The use of non HDL-C has been suggested as a better index of CHD risk and treatment (Frost and Havel, 1998). In this study $46 \%$ of the vegetarians and only $27 \%$ of the fish eaters had a non-HDL-C greater than $160 \mathrm{mg} / \mathrm{dL}$. The study concludes that consumption of fish in the regular diet improves the lipid status and thereby has a preventive role in CVD. The results of the present work were limited by the sample size. A large sample size study may be able to give a better insight.

\section{References}

Allain, CC., Poon, LS, Chan, CS., Richmond, W., Fu, PC. 1974. Enzymatic determination of total serum cholesterol. Clin Chem. 20(4): 470- 475.

Austin, MA.1991. Plasma triglycerides and coronary heart disease. Arterioscler Thromb. 11, 2-14.

Begg, A., Connolly, S., Halcox, J., Kaba, A., Main L., Williams, H., Yellon, D. 2012. Omega 3 fatty acids in cardiovascular disease: re-assessing the evidence. Brit J Cardiol 19:79-84 doi:10.5837/bjc.2012.016.

Bulliyya, G. 2002. Influence of fish consumption on the distribution of serum Cholesterol in lipoprotein fractions: comparative study among fish-consuming and non-fishconsuming population. Asia Pacific J Clin Nutr. 11(2): 104-111.

Chowdhury, R., Stevens, S., Gorman, D., Pan, A., Warnakula, S., Chawdhury, S., et al., 2012. Association between fish consumption, long chain omega 3 fatty acids and risk of cerebrovascular disease: Systemic review and MetaAnalysis. Brit.Med J. 345:1-9.

Frost, PH., Havel, RJ. 1998. Rationale for use of non-high density lipoprotein rather than low density lipoprotein cholesterol as a tool for lipoprotein cholesterol screening and assessment of risk and therapy. Am J Cardiol. 8131B, 26B.

Gofman, JW, Young, W., Tandy, R. 1996. Ischaemic heart disease, 
atherosclerosis and longevity.

Circulation. 34: (4) 679-692.

Goldbourt, U., and Medali, JH. 1997.

Cholesterol in alpha lipoprotein and clinical myocardial infarction. In : Gordon T, Castaelli WP, Hjotland MC, Kannel WB, Dawber TR. High density lipoprotein as a protective factor against coronary heart disease. Am J Med. 62, 707-713.

Gordon , J., Probstfield, JL., Garrison, R J., Neaton, JD., Castelli, WP., Knoke, JD., Jacobs Jr., DR., Bangdiwala S., Tyroller HA. 1989. High density lipoprotein cholesterol and cardiovascular disease. Circulation. 9, 9-15.

Hokanson, JE., and Austin, MA. 1996. Plasma triglyceride is a risk factor for cardiovascular disease independent of high density lipoprotein cholesterol; a meta analysis of population based prospective studies. J. Cardiovasc Risk. 3(2):213-219.

Jacobs, NJ, and Van Denmark, PJ. 1960. Enzymatic determination of serum triglycerides. Arch Biochem Biophy. 88:250-255.

Kamel, M., Barkia, A., Hamdaoui, M., Ketata, H., Kassis, M., Nasri, M., Aouidet, A. 2011. Comparison of some anthropometric and biologic parameters in two groups of tunision infants. Afr J Biotechnol. 10(20):4005-4010.

Kondreddy, R., Chenak, A., Akula, US., Garabet, A., Srikumar, S., Jarari, AM., Peela, JR.2012. Study of lipid profile in coronary heart disease patients in Libya. J Biomed Sci 1(4:3):1-9.

Krishnan, MN. 2012. Coronary heart disease and risk factors in India-On the brink of an epidemic? Ind heart J. 64:364367.

Kumar, A., Sivakansan, R. 2008. Serum lipid profile abnormality in predicting the risk of myocardial infarction in elderly normolipidemic patients in South Asia: A caes-contrlled study. The Int J Alt Med 6(2): 1-6.

Lozano, JV. Pallares, V., Cea-Calvo, L., Listerri, JL., Fernandez-Perez. C., Marti-Canales, JC. Aznar J., GilGuillen, V., Redon, J. 2008. Serum lipid profiles and their relationship to cardiovascular disease in the elderly: the PREV-ICTUS study. Curr Med Res Opin. 24 (3):659-670.

McLennan, PL. 2014. Cardiac Physiology and efficacy of dietary fish oil clarified through cellular mechanism of omega 3 polyunsaturated fatty acid. Eur $\mathbf{J}$ Appl Physiol 114(7):1333-56.

Minihane, AM. 2013. Metabolic Syndrome, diabetes mellitus, cardiovascular and neurodegenerative disease. Fish oil omega fatty acids and cardiometabolic health, alone or with statins. Eur J Clin Nutr.67:536540.doi:10.1038/ejen.2013.19.

Najafi, M., and Sheikhvatan M. 2013. Gender Differences in Coronary Artery Disease: Correlation Study on Dietary Pattern and Known Cardiovascular Risk Factors.Int.Cardiovas.Res.J. 7(4):124129.

Ooi, EMM, Watts, GF, WK Ng, T., Barrett, PHR. 2015. Effect of Dietery Fatty Acids on Human Lipoprotein Metabolism. A Comprehensive update. Nutri $7: 4416-$ 4425.doi.10.339/nu/06446.

Qi, K., Fan, C., Jiang, J., Zhu, H., Menq, Q., Deckelbaum, RJ. 2008. Omega-3 fatty acid containing diets decrease plasma triglyceride concentration in mice by reducing triglyceride synthesis and enhancing the blood clearance of triglyceride -rich particles. Clin.Nutr. 27(3):424-430. 
Reddy, KS, Prabhakaran, D., Chaturvedi, V., Jeemon, P., Thankappan, KR., Ramakrishna, L., et.al., 2006. Methods for establishing a surveillance system for cardiovascular disease in Indian industrial populations. Bull World Health Organ. 84:461-469.

Roatz, SK., Silverstein, JT., Jahns, L., Picklo, MJ. 2013. Issues of fish consumption for Cardiovascular Disease Risk Reduction. Nutr. 5(4):1081-1097.doi:10.3390/nu 5041081.

Tavia, G., William, P., Castelli, MD., Marthana, CH., William, BK., Thomas, RD. 1977. High density lipoprotein as a protective factor against density lipoprotein as a protective factor against coronary heart disease the Framingham study. The Am J Med. 62, 707 - 713.
Tsutsumi, A.2015. Prevention and management of work-related cardiovascular disorders. Int J Occup Med Environ Health. 28(1):4-7.

Upadhyaya, R. 2015. Emerging Risk Biomarkers in Cardiovascular Disease and Disorders. J Lipids. http:/dx.doi.org/10.115/2015/971453.

Williams, P., Robinson, D., Bailey, A.1979. High density lipoprotein and coronary risk factor in normal men. The Lancet. 313(8107):72-75.

Xin, W., Wei, W., Li, X. 2012. Effect of fish oil supplementation on inflammatory markers in chronic heart failure-A Meta analysis of randomized controlled trails. BMC Cardiovasc Disord. 12; (77):1-11.

\section{How to cite this article:}

Asha Prabhu, Manjula Shantaram and H.P.Kedilaya. 2016. A Comparative Study of Lipid Profile in Vegetarians and Fish eaters of Selected Areas in Coastal Karnataka, India. Int.J.Curr.Res.Aca.Rev. 4(2): 164-169. doi: http://dx.doi.org/10.20546/ijcrar.2016.402.020 